\title{
18. Aportaciones al APIB
}

N. MARCOS

Departamento de Biología Vegetal I, Facultad de Biología Universidad Complutense, MADRID

Osmunda regalis $\mathrm{L}$.

TOLEDO: Los Navalucillos, Sierra Fría, 30SUJ5781, 1-VI-1986; en bosques ribereños, a $800 \mathrm{~m}$, Marcos \& Matute (MA 349618).

Polypodium interjectum Shivas

TOLEDO: Los Navalucillos, Sierra Fría, 30SUJ5780, 14-III-1986, en roquedos cuarcíticos, a $870 \mathrm{~m}$, Marcos \& Matute (MA 349619).

Notholaena marantae (L.) Desv. subsp. marantae

TOLEDO: Los Yébenes, Sierra del Rebollarejo, 30SVJ1971, 14-IV-1981, en taludes pedregosos, a $1120 \mathrm{~m}$, Marcos (MA 258675).

Anogramma leptophylla (L.) Link

TOLEDO: Navalcán, Embalse de Navalcán, 30SUK1736, 7-IV-1986, en grietas de rocas graníticas, a 400 $\mathrm{m}$, Marcos \& Bonet (MA 349616).

Asplenium ceterach L.

CIUDAD REAL: Fuente el Fresno, Sierra de la Cueva, 30SVJ4042, 5-III-1981, en roquedos cuarcíticos, a $1100 \mathrm{~m}$, Marcos (MA 34615).

Athyrium filix-femina (L.) Roth

TOLEDO: Los Navalucillos, - Sierra Fría, 30SUJ5978, 12-VII-1986, en sotobosque de robledal, a $1000 \mathrm{~m}$, Marcos \& Matute (349617).

Cheilanthes $x$ iberica Rasbach \& Reichst.

TOLEDO: Urda, Sierra de Enmedio, 30SVJ3649, 12-III-1980, en roquedos cuarcíticos, a $900 \mathrm{~m}$, Marcos \& Muñoz (MA254403).

Cheilanthes x kochiana Rasbach, Reichst. \& Schneller TOLEDO: Los Yébenes, Sierra del Rebollarejo, 30SVJ1975, 14-IV-1981, en roquedos cuarcíticos, a $1120 \mathrm{~m}$, Marcos (MA 346471).

\section{Notas pteridológicas de Galicia, II}

F.X. SOÑORA \& S. ORTIZ

Laboratorio de Botánica, Departamento de Bioloxía Vexetal

Facultade de Farmacia, Universidade de Santiago

Huperzia selago (L.) Bernh. subsp. selago

A CORUÑA: Vixía de Herbeira, A Capelada (Santa Marta de Ortigueira), 29TNJ8442, 600 m s.n.m., 28.III.88, en el seno de un brezal higrófilo 